\title{
AS ATRIBUIÇÕES E AS OPORTUNIDADES DE FORMAÇÃO DO PROFESSOR DE SALA DE RECURSOS MULTIFUNCIONAIS: UMA PESQUISA EM ROLIM DE MOURA-RONDÔNIA
}

Flávia Pansini ${ }^{\mathrm{i}}$

Edi Carlos de Souzaii

\begin{abstract}
Resumo: O artigo aborda as atribuições desempenhadas por uma professora que atua em sala de recursos multifuncionais, confrontando às oportunidades de formação a que teve acesso. A pesquisa foi realizada em uma escola municipal de Rolim de Moura-Rondônia, utilizando entrevistas e registro fotográfico. Os resultados mostram que a professora possuía quantidade significativa de atribuições às quais não podiam ser desempenhadas com qualidade tendo em vista a reduzida jornada de trabalho. Além disso, a maioria dos cursos a que teve acesso foi custeada pela própria docente e apresentava carga horária restrita e conteúdos simplificados. Em síntese, a pesquisa mostra que a preocupação maior é com a quantidade de alunos atendidos e não com a qualidade desse atendimento.

Palavras-chave: Sala de recursos multifuncionais. Formação docente. Educação especial.

\section{THE ATTRIBUTIONS AND THE TRAINING OPPORTUNITIES OF MULTIFUNCTIONAL RESOURCES ROOM TEACHER: A RESEARCH IN ROLIM DE MOURA-RONDÔNIA}

\begin{abstract}
The article discusses the assignments performed by a teacher who works in a multifunctional resources room, confronting the training opportunities she had access to. The research was carried out in a municipal school in Rolim de Moura-Rondônia, using interviews and photographic records. The results show that the teacher had a significant amount of assignments that could not be performed with quality considering the reduced working hours. In addition, most of the courses she had access to were funded by the teacher herself and presented restricted hours and simplified content. In summary, the research shows that the greatest concern is with the number of students attended and not with the quality of this service.
\end{abstract}

Keywords: Multifunctional resources room. Teacher training. Special education.

\section{Introdução}

Atualmente o atendimento educacional especializado para os estudantes públicos alvo da educação especial no Brasil é realizado prioritariamente nas salas de recursos multifuncionais (SRMs). Estas salas estão presentes na política de educação especial brasileira desde a década de 1970, porém foi apenas na década de 2000 que elas passaram a receber o adjetivo de multifuncional.

Conforme a Portaria Normativa $\mathrm{N}^{\mathrm{o}}$ - 13, de 24 de abril de 2007, a sala de recursos multifuncionais "é um espaço organizado com equipamentos de informática, ajudas técnicas, 


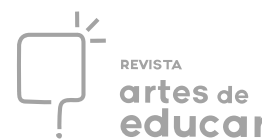

materiais pedagógicos e mobiliários adaptados, para atendimento às necessidades educacionais especiais dos alunos" (BRASIL, 2007). Além disso, deve contar com um professor especialista para desenvolver as atividades que são próprias desse ambiente particular. O objetivo principal da Sala de Recursos Multifuncionais é garantir a realização do atendimento educacional especializado (AEE), o qual, por sua vez, é definido como "conjunto de atividades, recursos de acessibilidade e pedagógicos organizados institucional e continuamente" (BRASIL, 2011, p. 3), permitindo complementar e suplementar a formação dos estudantes com deficiência, transtornos globais do desenvolvimento e altas habilidades, mediante o apoio permanente e limitado no tempo e na frequência deles às salas de recursos multifuncionais.

Conforme dados da Secretaria de Educação Continuada, Alfabetização, Diversidade e Inclusão (SECADI) em 2011, já havia no Brasil 39272 iii SRMs. A ampliação não parou por aí! Dentre os 5.246 municípios que no ano de 2013 possuíam matrículas de estudantes público-alvo da educação especial nas redes públicas de ensino, 5.020 (96\%) aderiram ao Programa SRMs. Nesse mesmo ano, foram adquiridos equipamentos de tecnologia assistiva, mobiliário e material pedagógico acessível para atualizar 13.500 SRMs existentes e implantar 4.000 novas.

Para o ano 2014, a meta era atingir a implantação de 42.000 novas salas e a atualização de 30.000 implantadas no período de 2005 a 2010 (SECADI, 2014). Tais metas foram previstas como uma das principais ações e programas de responsabilidade do Ministério da Educação no Plano Plurianual (PPA) 2012-2015, visando promover a organização e a oferta do AEE nas escolas públicas, garantindo o acesso, a participação e a aprendizagem dos estudantes públicoalvo da educação especial.

Considerando que, em junho de 2015 o MEC divulgou um relatório contendo os principais indicadores da educação especial, no qual contabilizou o total de 41751 SRMs em funcionamento no país (MEC/INEP, 2015), isso representa, após sete anos de institucionalização do Programa de Implantação de Salas de Recursos Multifuncionais, crescimento absoluto de cerca de $5.785,71 \%$ por cento ${ }^{\text {iv }}$.

Assim, tendo em vista que atualmente as salas de recursos multifuncionais estão presentes na maioria dos municípios brasileiros, uma questão que se coloca como importante diz respeito ao profissional que atua neste espaço específico. Nesse sentido, esta pesquisa voltou-se para o estudo das atribuições desempenhadas pelo professor responsável pelo atendimento educacional especializado em salas de recursos multifuncionais, confrontando-as com as oportunidades de formação. Para isso, dividimos o texto em duas partes. Na primeira abordamos especificamente as questões referentes à formação dos professores que atuam nesse espaço e na 
segunda apresentamos a descrição dos resultados e análise do material coletado com ênfase nas atribuições e nas condições de formação.

\section{As atribuições e a formação de professores de salas de recursos multifuncionais}

De acordo com o Ministério da Educação (MEC), o professor que atua nas salas de recursos multifuncionais precisa desenvolver atividades que exigem conhecimentos específicos da área de educação especial. Entre os conhecimentos necessários às atividades próprias do AEE, a Resolução CNE/CEB n.4/2009 define que o professor da sala de recursos multifuncionais precisa ter domínio da Língua Brasileira de Sinais (LIBRAS), do ensino da Língua Portuguesa escrita para alunos com surdez, da Comunicação Aumentativa e Alternativa (CAA), do ensino do sistema Braile, do uso do soroban e das técnicas para a orientação e mobilidade para alunos cegos. Além destes, precisa ter conhecimentos sobre o ensino da informática acessível e do uso dos recursos de Tecnologia Assistiva (TA), ensino de atividades de vida autônoma e social, orientação de atividades de enriquecimento curricular para as altas habilidades/superdotação e promoção de atividades para o desenvolvimento das funções mentais superiores. (BRASIL, 2010).

Além dessa gama ampla de conhecimentos, o professor da sala de recursos multifuncionais deve desenvolver várias atribuições. Segundo o documento Salas de Recursos Multifuncionais: espaço para o atendimento educacional especializado, suas atribuições são:

\footnotetext{
- atuar, como docente, nas atividades de complementação ou suplementação curricular específica que constituem o atendimento educacional especializado dos alunos com necessidades educacionais especiais;

- atuar de forma colaborativa com o professor da classe comum para a definição de estratégias pedagógicas que favoreçam o acesso do aluno com necessidades educacionais especiais ao currículo e a sua interação no grupo;

- promover as condições para a inclusão dos alunos com necessidades educacionais especiais em todas as atividades da escola;

- orientar as famílias para o seu envolvimento e a sua participação no processo educacional;

- informar a comunidade escolar acerca da legislação e normas educacionais vigentes que asseguram a inclusão educacional;

- participar do processo de identificação e tomada de decisões acerca do atendimento às necessidades educacionais especiais dos alunos;

- preparar material específico para uso dos alunos na sala de recursos;

- orientar a elaboração de materiais didático-pedagógicos que possam ser utilizados pelos alunos nas classes comuns do ensino regular;

- indicar e orientar o uso de equipamentos e materiais específicos e de outros recursos existentes na família e na comunidade;
} 
- articular, com gestores e professores, para que o projeto pedagógico da instituição de ensino se organize coletivamente numa perspectiva de educação inclusiva (BRASIL, 2006, p.18).

Já a Resolução CNE/CEB n.4/2009 enfatiza que para atuar nas salas de recursos multifuncionais o professor deve ter formação inicial que o habilite para o exercício da docência e formação específica na educação especial. De acordo com o art. 13 da Resolução são atribuições do professor:

I - Identificar, elaborar, produzir e organizar serviços, recursos pedagógicos, de acessibilidade e estratégias considerando as necessidades específicas dos alunos público-alvo da Educação Especial;

II - Elaborar e executar plano de Atendimento Educacional Especializado, avaliando a funcionalidade e a aplicabilidade dos recursos pedagógicos e de acessibilidade;

III - organizar o tipo e o número de atendimentos aos alunos na sala de recursos multifuncionais;

IV- Acompanhar a funcionalidade e a aplicabilidade dos recursos pedagógicos e de acessibilidade na sala de aula comum do ensino regular, bem como em outros ambientes da escola;

$\mathrm{V}$ - Estabelecer parcerias com as áreas intersetoriais na elaboração de estratégias e na disponibilização de recursos de acessibilidade;

VI - Orientar professores e famílias sobre os recursos pedagógicos e de acessibilidade utilizados pelo aluno;

VII - ensinar e usar a tecnologia assistiva de forma a ampliar habilidades funcionais dos alunos, promovendo autonomia e participação;

VIII- estabelecer articulação com os professores da sala de aula comum, visando à disponibilização dos serviços, dos recursos pedagógicos e de acessibilidade e das estratégias que promovem a participação dos alunos nas atividades escolares (BRASIL, 2009, p.8-9).

Diante da diversidade de conhecimentos e em face da quantidade de atribuições, alguns pesquisadores (GARCIA, 2013; KASSAR, 2014) têm discutido a respeito da formação do professor de sala de recursos multifuncionais. Eles enfatizam que a organização da sala de recursos multifuncional, ao mesmo tempo em que exige muitas atribuições e conhecimentos por parte do professor, se choca com a realidade na qual há pouca oferta de formação, tanto inicial quanto em serviço. Segundo Garcia (2013, p. 115) sob o manto da multifuncionalidade, o atendimento aos estudantes da educação especial:

Passou de mais especializado, com cada professor atuando com alunos com características comuns relacionadas à deficiência (cegueira, surdez, deficiência física, mental, múltipla), para uma atuação mais abrangente, na qual um mesmo professor atua com alunos com as mais diversas características. 
Em relação à formação inicial, Hermes e Lunardi-Lazarin $(2012$, p. 4) relatam que "em 2006, dos 54.625 professores nessa função, 0,62\% registram ensino fundamental e $24 \%$ ensino médio". As mesmas autoras apontam um crescimento significativo no ensino superior, pois enquanto em 1998 apenas 45,7\% possuíam graduação, em 2008 a quantidade de docentes que possuíam nível superior já representava 75,2\% dos professores da rede pública de ensino. Ainda em 2008, uma boa parcela destes professores $(77,8 \%)$ afirmou possuir curso específico nesta área, ou seja, em educação especial.

Entretanto, Hermes e Lunardi-Lazarin (2012) ponderam em relação aos dados apresentados que eles se referem apenas aos professores que atuam no atendimento educacional especializado e não ao conjunto dos docentes que atuam com estudantes alvo da educação especial nas salas de aula regulares. Esses docentes, via de regra, se graduaram em cursos que ofereciam apenas uma disciplina na área, pois segundo Kassar (2014), há poucos cursos disponíveis nas universidades brasileiras, de modo que a maior parte dos docentes possui conhecimentos muito superficiais em relação à educação especial.

Ainda sobre este aspecto, Bueno (2012) afirma que a formação do professor especializado não tem sido incorporada como política integrada pelos sistemas de ensino e pelas universidades brasileiras, prevalecendo os cursos de aperfeiçoamento sem qualquer padrão estabelecido. No entanto, essa realidade tem sido pouco evidenciada pelas investigações realizadas na área da educação especial, seja no sentido de incorporar essa ausência às análises sobre a atuação docente, seja no sentido de desenvolver pesquisas específicas que visem "levantar, organizar, classificar e analisar as políticas em ação dos diferentes sistemas de ensino e das instituições de ensino superior" (BUENO, 2012, p. 292).

No que diz respeito à formação continuada, as pesquisas apontam uma série de problemas como a precariedade dos cursos oferecidos e a superficialidade teórica presente nos materiais utilizados. Em relação aos cursos, geralmente são realizados na modalidade à distancia; mesmo quando possuem alguma carga horária presencial não suprem as necessidades de formação uma vez que a maioria deles tem curta duração. Muitos deles têm uma duração de 40 horas anuais o que não permite que um professor se torne habilitado tendo que aprender como é a função de professor do AEE dentro da própria sala de recursos multifuncionais. Um exemplo dessa precariedade é descrita por Garcia ao se referir a um curso "caracterizado como de extensão" com "carga horária de 180 horas, sendo 156 horas a distância (87\%) e apenas 24 horas presenciais (13\%)" (GARCIA, 2013, p. 114).

Além da carga horária reduzida, os materiais utilizados não possuem qualquer articulação sobre as temáticas trabalhadas, mas apenas fornecem sugestões de como realizar as atividades Revista Interinstitucional Artes de Educar. Rio de Janeiro, V. 4, N.1- pág. 117 - 131 - (jan. - abr. de 2018): "Questões contemporâneas sobre a Educação Especial na Perspectiva da Educação Inclusiva” - 
com as crianças. Assim, pode-se afirmar que os materiais produzidos para os cursos de formação possuem em seus conteúdos uma superficialidade por que não deixa claro o porquê de ensinar determinado conteúdo, além de não apresentar com clareza os referenciais teóricos envolvidos na área da educação especial.

Diante desses problemas, Garcia (2013) explica que atualmente não é levada em conta a necessidade de formação adequada para os professores que atuam nas salas de recursos multifuncionais. Ao contrário, busca-se apenas um tipo de "conformação docente", dentro de um modelo burocrático em que o poder público transfere a responsabilidade toda para o professor. Segundo a autora, a conformação docente é mais uma das estratégias para tornar os professores mais alienados e conformados com o atual cenário da educação. Essa estratégia tem como principal finalidade colocar a culpa pela má formação e pelo insucesso dos educandos ou a ineficácia dos atendimentos no próprio professor. Conforme a autora:

\begin{abstract}
A mudança de um modelo burocrático para uma gestão gerencial transfere aos professores não só a responsabilidade pela sua própria profissionalização, mediante a busca individual de formação, mas também pelo alcance dos objetivos e metas da própria política. Caso ela não tenha sucesso, isso recai sobre a competência docente (GARCIA, 2013, p. 110).
\end{abstract}

Nesse sentido, a busca pela formação deve ser realizada de forma individual pelo próprio professor. Essa busca, muitas vezes se dá em face das pressões exercidas sobre o próprio professor que almeja dar conta dos objetivos e atribuições a serem desempenhadas. Além disso, segundo Hermes e Lunardi-Lazarin, a cobrança excessiva pelos resultados leva ao "desejo de formação", ou seja, "os professores manifestam a necessidade de formação acerca das necessidades educacionais especiais", imperando "o desejo docente pela formação continuada. Essa necessidade de formação marca a docência de tal forma que, para ser professor do AEE, deve-se fazer um curso do AEE” (HERMES; LUNARDI-LAZARIN, 2012, p.6).

Analisando as atribuições exigidas do professor da sala de recursos multifuncionais e confrontando com todos esses problemas levantados pelas pesquisas teóricas referentes à formação, descrevemos a seguir alguns dos resultados alcançados com a pesquisa.

\title{
O que mostram os dados?
}

A pesquisa foi realizada em uma escola do município de Rolim de Moura, localizado na região da Zona da Mata do Estado de Rondônia, na região Norte do Brasil. Em 2016 a população total do município era de 56.664, segundo dados do Instituto Brasileiro de Geografia e Estatística 
- IBGE (IBGE, 2017). Os dados foram coletados durante o primeiro semestre de 2017, mediante entrevistas e registros fotográficos.

Segundo dados do Instituto Brasileiro de Geografia e Estatística (IBGE), o município de Rolim de Moura possuía em 2016, um total de 8.885 alunos matriculados no ensino fundamental e 2.191 matrículas no ensino médio (IBGE, 2017). Vale salientar que no ano de 2017 esse número era bem maior, uma vez que o município passou a atender em sua rede alunos antes matriculados na rede estadual.

Quanto à escola na qual a pesquisa foi desenvolvida, trata-se de uma instituição localizada em um bairro periférico distante do centro da cidade. As famílias atendidas são, em geral, de baixa renda e recebem recursos assistenciais do governo federal. A escola conta com aproximadamente 240 alunos matriculados e atende apenas os anos iniciais do ensino fundamental, e conta com um corpo docente de aproximadamente 14 professores.

Dentro dessa escola, o foco da pesquisa recaiu sobre a sala de recursos multifuncionais que foi implantada no ano de 2014 no âmbito do Programa de Implantação de Salas de Recursos Multifuncionais. Na sala eram atendidos 13 estudantes sendo 11 com deficiência intelectual, um autista e um com Síndrome de Down. Entre os 11 alunos com deficiência intelectual, três não possuíam laudo ou diagnóstico confirmado. Esse dado mostra que no município de Rolim de Moura, o perfil dos alunos atendidos pela sala de recursos multifuncionais, não difere muito da realidade de outros municípios brasileiros, uma vez que as pesquisas mostram que o maior público é de alunos com deficiência intelectual (DELEVATI, 2012). Como entre os onze atendidos, apenas oito possuem diagnóstico fica a pergunta se realmente esses três alunos possuem deficiência, pois segundo Bueno (2004), o encaminhamento de crianças com dificuldades de aprendizagem para a educação especial é uma realidade histórica que ainda não foi superada no Brasil.

Quanto ao trabalho desenvolvido pela professora, verificamos que a docente possuía regime de trabalho de 40 horas semanais nas quais assumia quantidade significativa de atribuições. No quadro abaixo apresentamos um resumo da quantidade de atividades realizadas pela professora e a carga horária total para cada uma delas. 
QUADRO 1: ATIVIDADES REALIZADAS PELA PROFESSORA

\begin{tabular}{|l|l|}
\hline \multicolumn{1}{|c|}{ Quantidade de horas } & \multicolumn{1}{|c|}{ Atividades } \\
\hline 30 horas & Atendimento aos alunos \\
\hline 10 horas & Planejamento; \\
& Elaboração de atividades, materiais pedagógicos e recursos de \\
& tecnologia assistiva; \\
& Visita à casa dos alunos e orientação aos pais; \\
& Participação em atividades extraclasse; \\
& Auxílio ao professor da sala regular; \\
& Acompanhamento junto a outros profissionais: fonoaudióloga e \\
& psicóloga; \\
& Encaminhamento para avaliação diagnóstica. \\
\hline
\end{tabular}

Nota-se que para garantir o total de horas obrigatórias para o atendimento, a professora acabava tendo à sua disposição um tempo que consideramos irrisório para a realização das outras atribuições. Tendo em vista que o planejamento era realizado sempre as terças-feiras pela manhã consumindo quatro horas semanais, sobravam apenas seis horas para a realização das outras atividades tornando praticamente impossível desenvolvê-las. Assim, dispondo de apenas 10 horas para a realização de atividades que não envolvem atendimento a professora menciona que:

A meu ver se for pra fazer tudo o que o MEC pede o tempo é sim insuficiente. Veja você que tirando o horário de atendimento com o aluno, tenho somente 10 horas semanal para essas atividades propostas, então de cara já vemos que é impossível a realização dessas atividades todas (Entrevista 29 de maio de 2017).

Com relação às trinta horas para o trabalho com os alunos a professora relata que procura focar as atividades mais no atendimento em grupos, distribuindo-o da seguinte maneira:

Os atendimentos tem a duração de 2 horas; por exemplo: se começa às 7 horas termina às 9 horas e assim por diante. $\mathrm{O}$ aluno deve somar 4 horas de atendimentos por semana. E sempre tento fazer da melhor maneira possível, muito embora eu reconheça que esse horário é pouco, mas se a carga horária para o atendimento fosse maior eu também não conseguiria planejar (Entrevista 29 de maio de 2017).

Dessa forma, a professora não tem condições de realizar um trabalho individual com cada aluno, pois dispõe de somente 30 horas para o atendimento. Caso necessitasse de atendimento individual seriam necessárias 52 horas para que todos os treze alunos pudessem ser atendidos por um período de quatro horas como estabelece a legislação. Nesse sentido, mesmo que fosse apenas para atender aos alunos a professora ficaria com um déficit de 12 horas visto que seu regime total de trabalho é de 40 horas. Vale lembrar que a maioria dos alunos atendidos pela professora possuía deficiência intelectual e conforme o MEC (2006), o professor que atende esse 
tipo de aluno na SRMs deve priorizar o "desenvolvimento dos processos mentais, oportunizando atividades que permitam a descoberta, inventividade e criatividade" (BRASIL/MEC, 2006, p. 23). Nesse sentido, ao professor cabe desenvolver as seguintes atribuições:

- realizar atividades que estimulem o desenvolvimento dos processos mentais: atenção, percepção, memória, raciocínio, imaginação, criatividade, linguagem, entre outros;

- proporcionar ao aluno o conhecimento de seu corpo, levando-o a usá-lo como instrumento de expressão consciente na busca de sua independência e na satisfação de suas necessidades;

- fortalecer a autonomia dos alunos para decidir, opinar, escolher e tomar iniciativas, a partir de suas necessidades e motivações;

- propiciar a interação dos alunos em ambientes sociais, valorizando as diferenças e a não discriminação;

- preparar materiais e atividades específicas para o desenvolvimento da aprendizagem dos alunos. (BRASIL/MEC, 2006, P. 23).

Diante dessa lista, normalmente a professora acaba tendo que priorizar alguns aspectos em detrimento de outros. Normalmente, acaba focando nas dificuldades dos alunos em sala de aula regular, pois caso contrário, haveria uma sobrecarga muito grande de trabalho. Assim, as condições de atendimento nem sempre são favoráveis, pois são muitas as atribuições com uma reduzida carga horária. O "peso" dessas atribuições se torna ainda maior em face das reduzidas oportunidades de formação acessíveis para a professora que mencionou aspectos referentes tanto à formação inicial, quanto a formação em serviço.

Quanto à formação inicial, a professora se graduou em Pedagogia, porém durante o curso houve oferta de apenas uma disciplina voltada para estas questões com carga horaria total de 80 horas. Devido a pouca carga horária, essa formação abordou aspectos gerais, focalizando algumas características dos estudantes da educação especial, além da legislação e outros aspectos referentes à política educacional. Conforme a professora:

Você sai da faculdade sonhando muito e quando fazemos uma graduação, achamos que vai ser fácil. O que não é real. Vemos que o professor do ensino regular é preparado para ensinar o aluno que aprende entre aspas. E quando nos deparamos com as situações da diversidade é aonde surgem as dificuldades. E ai é o momento onde precisamos nos adequar para a realidade, planejando para todos. Porque você tem que ter em mente que o planejamento deve ser sempre com foco nas necessidades da criança e nunca nas do professor! (Entrevista 29 de maio de 2017).

Assim como essa professora, a maioria dos que trabalham em sala de recursos multifuncionais não possui formação inicial em áreas específicas da educação especial, contando apenas com cursos de especialização ou de aperfeiçoamento. Segundo Garcia, os documentos 
representativos da política de educação especial brasileira contribuem para essa realidade, pois "não contêm tematizações a respeito da formação inicial, mas disputam o espaço da formação em serviço" (GARCIA, 2013, p. 113).

Ainda segundo essa autora, o foco atual da política de educação especial no Brasil, é o programa de implantação de salas de recursos multifuncionais. Nesse sentido, a ênfase na formação em serviço é corroborada pela natureza do atendimento ofertado que visa atender a todos os alunos da educação especial, ou seja, alunos com deficiências, com transtornos globais do desenvolvimento e altas habilidades/superdotação. Dessa forma, Garcia (2013, p. 113) enfatiza que há uma "preocupação em formar um novo professor de educação especial, reconvertido, que não vai atuar nas instituições especializadas, classes especiais ou salas de recursos de atendimento por área de deficiência" e sim no "AEE realizado na SRM".

Ocorre que em muitas redes de ensino, nem mesmo a formação em serviço é ofertada aos professores que atuam na sala de recurso multifuncional. Esse é o caso da professora em questão uma vez que ao falar das formações que teve acesso, a professora cita algumas que foram oferecidas por uma instituição especializada, além de um curso de pós-graduação em educação especial e outros cursos de menor duração, sendo a maioria deles custeados com recursos próprios. Nas palavras da professora:

Os cursos que faço são todos custeados; por exemplo: o Neuro Saber é um curso caro por volta de 200 Reais mensais. Tem outros mais baratos, só que mais inferiores. O Neuro Saber tem muito vídeo, já o Educa é muita leitura, e por isso tenho mais dificuldades. (Entrevista, 29 de maio de 2017).

Esses dois cursos foram pagos com recursos próprios e evidenciam que a formação tem ficado mais a cargo do próprio professor do que do Estado. Dessa forma, ressaltamos que o comprometimento do professor com o seu trabalho o leva ao interesse de realização de cursos que deveriam ser oferecidos gratuitamente. Nessa perspectiva, Hermes e Lunardi-Lazarin (2012, p. 5) afirmam que aquilo que "estava proposto na Política Nacional, ou seja, os conhecimentos gerais para o exercício da docência e os conhecimentos específicos da área para atuação no AEE ou na escola inclusiva tornam-se um desejo docente". Esse desejo é manifestado pela professora no seguinte fragmento:

Ah! Eu sempre leio muito, como tenho uma amiga que sempre está fazendo cursos, ela vai me passando alguma coisa e sempre vamos lendo juntas e discutindo as mesmas ideias. Nos dias de hoje os cursos de formação são muito online, de minha parte confesso que não tenho muita paciência para os cursos online e prefiro os presenciais. Mas sempre que tem em algum lugar procuro fazer. Por exemplo: a poucos dias fiz um de autismo em Cacoal e um outro em Ji Paraná. Da SEMEC tem um com a psicóloga 
também, só que mais direcionado para quem está em sala de aula; participo e sempre trago alguma coisa pra minha sala também. E tenho participado de alguns também no Centro Educacional com o professor Nelson com o qual eu tenho mais contato, que sempre os cursos da SEMEC são direcionados para ele ministrar (Entrevista 29 de maio de 2017).

O fragmento mostra que diante da pouca oferta de cursos, a professora acaba buscando alternativas diversas que contribuem com sua auto-formação. Essa realidade comprova aquilo que as pesquisas sobre formação de professores de salas de recursos multifuncionais evidenciam como sendo uma omissão do Estado com a formação, o que tem resultado em professores com poucos conhecimentos e reduzidas oportunidades de aprendizagem tanto para ele, como para os alunos atendidos.

Com uma base teórica frágil o professor acaba tendo que adquirir os conhecimentos dentro da própria sala de aula, ou seja, no próprio exercício da profissão o que não trás nenhum tipo de segurança para os profissionais que atuam no AEE, tampouco para os alunos que dependem deste tipo de ensino por que não encontram o suporte necessário para o seu desenvolvimento intelectual. Conforme acentua Shiroma (2003, p. 67) trata-se de uma supervalorização do “conhecimento construído 'na' e 'pela' experiência, um tipo de conhecimento tácito que não pode ser construído de outra forma senão na prática profissional”. Conforme Garcia (2013, p. 110):

Tal modelo de formação guarda como pressuposto que os professores devem ser formados no próprio ambiente de trabalho, as escolas, e que a base de sua formação é a própria prática docente, sendo dispensável uma formação universitária e o estudo das teorias pedagógicas, entre outros conhecimentos.

Essa afirmação mostra que na maioria dos casos, a formação docente passa a ganhar feições de ajuste, treinamento e reciclagem, distanciando-se de uma sólida formação docente necessária ao exercício da profissão. Além disso, justifica e ajuda a disseminar as ideias defendidas pelos Organismos Internacionais segundo os quais, a formação teórica não possui qualquer valor para o profissional, ou seja, o que vale não é aquilo que se aprende em um curso universitário mais sim aquilo que é aprendido no próprio exercício da profissão.

No caso da professora participante dessa pesquisa ela afirma que é cobrada pelos resultados e que o governo federal envia algumas obras para leitura, sem qualquer tipo de orientação profissional e espera que esse material seja estudado individualmente por cada professor especialista. Segue abaixo, figura contendo algumas das obras disponibilizadas para a professora: 
Figura 1: Textos teóricos e legais presentes na SRMs da escola

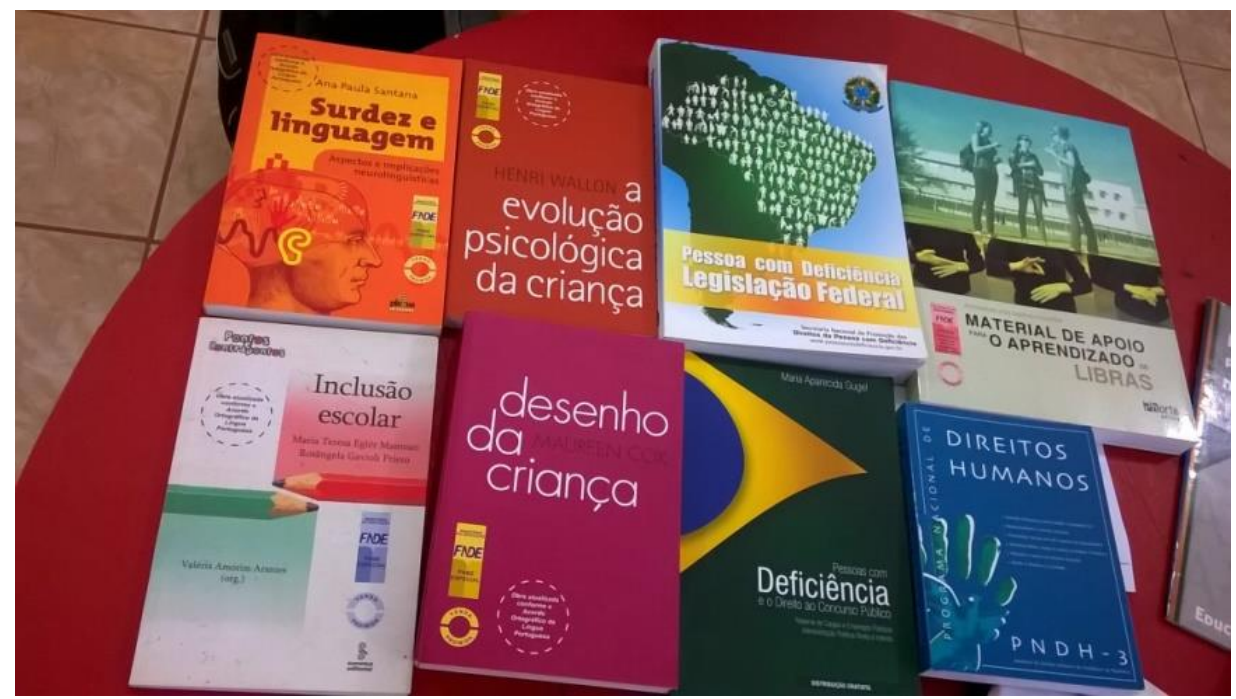

Fonte: Arquivos da pesquisa

Verifica-se, que além do ecletismo teórico presente nos materiais, algumas áreas são priorizadas em detrimento de outras, pois é possível verificar uma prevalência de livros voltados para a área da surdez. Além disso, espera-se que os professores leiam obras de referência como o livro de Henri Wallon que aparece na foto, sem ter tido nenhuma oportunidade de estudo que aprofundasse as questões levantadas pelo autor. Assim, a professora diz que ela raramente irá ler uma obra dessas por dois motivos: primeiro pela dificuldade em se apropriar das informações e segundo, porque não há carga horária disponível para o estudo.

Mesmo que ela leia as obras, os livros não oferecem conhecimentos suficientes para que ela possa desenvolver atividades que são próprias da sala de recursos multifuncional como desenvolver recursos de tecnologia Assistiva, dominar o uso do braile, e outros recursos como programas de computador e impressora braile. Todavia, o Ministério da Educação utiliza o envio dos materiais como modo de pressionar o professor, ao mesmo tempo em que transmite a ideia de que está realizando uma grande revolução na educação especial ao "retirar os professores da condição de leigos e transformá-los em profissionais" (Garcia, 2013, p. 110).

A qualidade dessa suposta "profissionalização" parece não preocupar os responsáveis pelo planejamento educacional no país, como foi possível constatar mediante as reflexões teóricas e os dados apresentados nessa investigação. Embora esses dados se refiram a uma clientela específica da educação especial, não podemos esquecer que essa é apenas uma modalidade e que por isso, seus problemas, são os mesmos que afetam a educação geral. 


\section{Considerações finais}

Nessa pesquisa procuramos estudar das atribuições desempenhadas pelo professor responsável pelo atendimento educacional especializado em salas de recursos multifuncionais, confrontando-as com as oportunidades de formação. Após análise dos dados, podemos inferir algumas considerações que nos ajudam a entender melhor a realidade concreta.

Verificamos que a carga horária da professora é bastante reduzida e que ela possui uma quantidade significativa de atribuições divididas entre o atendimento aos alunos e outras tarefas externas e internas como o planejamento, elaboração de materiais, auxílio aos professores de sal regular, etc. Para essas atividades a professora dispõe de apenas dez horas semanais para realizálas.

A realidade mostra, assim, que há muitos alunos e poucos professores contratados para essa atividade. Entre os fatores que podem estar por traz disso, enfatizamos a redução de custos financeiros, pois ao exigir que um único professor atenda um número maior de alunos, num único espaço e com várias deficiências, o Estado deixa de investir os recursos obtidos da sociedade em construção de espaços, formação de professores, contratação de novos trabalhadores, etc.

Outro elemento que pode estar por traz dessa realidade é o fato de que, tanto na educação especial como também na educação geral, a maior preocupação não é com a formação de pessoas críticas, mas em preparar mão-de-obra barata para atender as exigências do mercado. Nesse sentido, a preocupação maior é com a quantidade de alunos que estão sendo atendidos e não com a qualidade desses atendimentos.

Dentre os aspectos abordados nessa pesquisa, as oportunidades de formação a que teve acesso à professora é um bom exemplo dessa ausência de preocupação com a qualidade. Os dados mostraram que os cursos realizados, em geral, não foram disponibilizados pelo Estado e sim oferecidos por instituições privadas, sendo todos custeados pela própria docente. Além do mais, os poucos cursos oferecidos pelo sistema público, foram de curta duração e não lhe deram suporte para desenvolver um bom trabalho.

Consideramos que esses elementos ocorrem justamente para impossibilitar que a classe trabalhadora, principal beneficiária das salas de recursos multifuncionais, tenha acesso a uma 
educação de qualidade. Nesse sentido, o Estado reproduz as propostas de um ensino precário ao mesmo tempo em que mantém inalterados os principais problemas que afetam a educação pública e, consequentemente, a educação dos estudantes público alvo da educação especial.

\section{Referências}

BRASIL/MEC. Sala de recursos multifuncionais: espaços para atendimento educacional especializado. Brasília, DF: Ministério da Educação: Secretaria de Educação Especial, 2006.

. MEC. SEESP. Manual de Orientação: Programa de Implantação de Salas de Recursos Multifuncionais. Brasília, 2010.

. MEC. Portaria Normativa $n^{\circ} 13$, de 24 de abril de 2007, que dispõe sobre a criação do

"Programa de Implantação de Salas de Recursos Multifuncionais". Brasília, 2007.

. Ministério da Educação. Resolução nº 04, de 02 de outubro de 2009a. Institui Diretrizes Operacionais para o Atendimento Educacional Especializado na Educação Básica, modalidade Educação Especial. Brasília, 2009. Disponível em: <

portal.mec.gov.br/dmdocuments/rceb004_09.pdf >. Acesso em: 30 de Nov. de 2010.

. Decreto $n^{\circ} 7.611$, de 17 de novembro de 2011, Dispõe sobre a educação especial, o atendimento educacional especializado e dá outras providências. Diário Oficial da União, 18 de setembro de 2011.

BRASIL. SECADI. Relatório de gestão exercício de 2013. Brasília/DF, 2014. Disponível em: <file://C:/Users/CArlos\%20e/Downloads/relatorio_gestao_exercicio_2013_secadi\%20(1).pdf> Acesso em 25 mar. 2015.

BRASIL.. Principais indicadores da educação de pessoas com deficiência. Disponível em: http://portal.mec.gov.br/index.php?option=com_docman\&view=download\&alias=17655-secadiprincipais-indicadores-da-educacao-especial\&category_slug=junho-2015-pdf\&Itemid=30192. Acesso em 20 jan. 2016.

BUENO, J. G. S. As pesquisas e a produção do conhecimento em educação especial: as investigações sobre políticas de educação especial no Brasil Distúrb Comun, São Paulo, 24(3): 285-297, dez. 2012. Disponível em: http://revistas.pucsp.br/index.php/dic/article/view/13144. Acesso em 15 mar. 2015.

. Educação especial brasileira: integração/segregação do aluno diferente. 2 ed. São Paulo: EDUC, 2004.

DELEVATI, A. de C. AEE: que atendimento é este? As configurações do atendimento educacional especializado na perspectiva da rede municipal de ensino de Gravataí/RS. Dissertação (Mestrado). Faculdade de Educação/Programa de Pós graduação em Educação. Universidade Federal do Rio Grande do Sul, Porto Alegre, 2012.

GARCIA, R. M. C. Política de educação especial na perspectiva inclusiva e a formação docente no Brasil. Rev. Bras. Educ., Rio de Janeiro, v. 18, n. 52, Mar. 2013. Disponível em: 
http://www.scielo.br/scielo.php?script=sci_arttext\&pid=S1413-

$24782013000100007 \& \operatorname{lng}=\mathrm{en} \& n r m=i s o>$. Acesso em 03 Mar. 2017.

HERMES, S. T.; LUNARDI-LAZARIN, M. L. Educação especial na perspectiva da educação inclusiva: capturas e mobilizações da docência no atendimento educacional especializado. $35^{\mathrm{a}}$ Reunião Anual da Anped: Porto de Galinhas-PE, 2012. Disponível em:

http://35reuniao.anped.org.br/images/stories/trabalhos/GT15\%20Trabalhos/GT15-2231_int.pdf. Acesso em 15 mar. 2017.

IBGE. Rondônia. Rolim de Moura. Disponível em:

http://cidades.ibge.gov.br/xtras/perfil.php?codmun=110028. Acesso em 03 de julho de 2017.

KASSAR, M. de C. M. A formação de professores para a educação inclusiva e os possíveis impactos na escolarização de alunos com deficiências. Cad. CEDES, Campinas, v. 34, n. 93, Mai 2014. Disponível em <http://www.scielo.br/scielo.php?script=sci_arttext\&pid=S010132622014000200207\&lng=en\&nrm=iso>. Acesso em 03 Mar. 2017.

SHIROMA, E. O. Política de profissionalização: aprimoramento ou desintelectualização do professor? Intermeio, Campo Grande, Universidade Federal de Mato Grosso do Sul, v. 9, n 17, p. 64-83, jan./jul., 2003.

\footnotetext{
${ }^{\text {i }}$ Docente do Departamento de Educação da Universidade de Rondônia, Campus de Rolim de Moura.

${ }^{i i}$ Pedagogo pela universidade Federal de Rondônia. Professor Especialista em educação especial (cegueira e baixa visão) da rede estadual de ensino de Rondônia.

iii Encontramos dificuldades com relação à exatidão do número real, pois há divergências no próprio INEP e nos documentos elaborados pelo MEC. Para citar dois exemplos, o site do Inep, em sua página de indicadores totaliza 39301 SRMs no final do ano de 2011. Todavia, quando pesquisamos por região o total indicado altera-se para 39272. O segundo exemplo está presente no documento "Orientações para Implementação da Política de Educação Especial na Perspectiva Da Educação Inclusiva Brasil, 2015” (MEC, 2015). Na página 17 desse documento consta que, até 2012, foram disponibilizadas 37.801 SRM; porém, outro gráfico presente na página 84 do mesmo documento traz o total de 28500 salas no mesmo ano de 2012.

${ }^{\text {iv }}$ Em 2007, ano de criação do Programa, o censo escolar registrou um total de 1251 SRMs existentes no Brasil. O cálculo foi efetuado tendo por base a quantidade de SRMs registradas no final de 2007 e no final de 2014 e o período equivalente entre elas. O mesmo foi realizado usando a seguinte fórmula matemática: " $(\mathrm{NF}-\mathrm{NI})$ : $\mathrm{t}$ ", ( período; $\mathrm{NF}=\mathrm{n}^{\circ}$ de salas no final do período e $\mathrm{t}=$ tempo/período).
} 